\title{
OS PRINCÍPIOS JURÍDICOS E SUA DENSIDADE NORMATIVA ${ }^{1}$
}

Ives Gandra da Silva Martins Filho²

\section{I) PRINCÍPIOS COMO PILARES DO DIREITO}

O que são pilares da CiênciaJ urídica? São justamenteos fundamentos que sustentam e iluminam a aplicação do Direito em cada ramo da Árvore J urídica.

Quais são esses pilares de sustentação do Direito? São os princípios que distingueme caracterizam cada um desses ramos.

No caso do Direito do Trabal ho, o pilar por antonomásia é a Encíclica Rerum Novarum, de 1891, do Papa Leão XIII, constituindo a Carta Magna daJ ustiça Social.

Os princípios básicos contidos na Encíclica Rerum Novarum, que plasmam a Doutrina Social Cristã e que serviram de norte e fundamento para as Constituições Sociais e legislação trabal hista no mundo inteiro são:

a) Princípio da Dignidade da Pessoa Humana ${ }^{3}-$ a pessoa humana tem uma dignidade essencial, por ser criada à

1 Conferêncial naugural do $52^{\circ}$ Congresso Brasileiro de Direito do Trabal ho, realizado no Centro de Convenções Rebouças no dia 25 de junho de 2012 e organizado pela LTR Editora, sob a coordenação do Professor Amauri Mascaro Nascimento.

2 Ministro do TST, onde preside a 7ạ Turma e a Comissão de Jurisprudência e Precedentes Normativos; Mestre em Direito pela UnB eProfessor dos Cursos de Pós-Graduação emDireito do Centro de Extensão Universitária (Escola de Direito do Instituto Internacional de Ciências Sociais).

3 Cfr. Encíclica RerumNovarum, n. 11.

Revista Esmat, Pal mas, Ano 5, № 5, pag. 219 a 240 - jan/jun 2013 
imagem e semelhança de Deus, em igualdade natural entre homem e mulher, estando acima de qualquer outra criatura material, razão pela qual não pode ser tratada como objeto ou mercadoria. Constitui o fim último da sociedade, que a ela está ordenada: não pode ser instrumentalizada para projetos econômicos, sociais ou políticos.

b) Princípio do Bem Comum ${ }^{4}$ - sendo o bem comum o conjunto das condições da vida social que permitem aos grupos e a cada um dos seus membros atingirem de maneira mais completa a própria perfeição, deve ser buscado como meta pela sociedade politicamente organizada que éo Estado. Assim, o objetivo do Estado não é apenas buscar a máxima felicidade do maior número, mas conseguir que todos possam atingir seus fins existenciais.

c) Princípio da Destinação U niversal dos Bens $5^{5}$ - Deus destinou a terra, com tudo que ela contém, para o uso de todos os homens e de todos os povos, de tal modo que os bens criados devem bastar a todos, com equidade, segundo a regra da justiça, inseparável da caridade. Razões de ordem jurídica (garantir o pacífico e ordenado desfrute dos bens da terra por parte de todos), econômica (garantir a solicitude e o interesse necessários para fazer render os bens) e política (garantir a liberdade individual frente ao Estado) justificam o reconhecimento da propriedade privada. No entanto, o direito à propriedade privada não é absoluto, mas deveatender à sua função social (responsabilidade

$4 \quad$ Cfr. Encídica RerumNovarum n. 19-20.

5 Cfr. Encídica RerumNovarum n. 3-7.

Revista Esmat, Palmas, Ano 5, № 5, pag. 219 a 240 - jan/jun 2013

221 
social pelos pobres e mais necessitados), estando subordinado à destinação universal dos bens (que não se confunde com o domínio comum detodos os bens).

d) Princípio da Subsidiariedade ${ }^{6}$ - o Estado não deve fazer aquilo que podem e devem fazer as pessoas e os grupos sociais menores, como as famílias, as escolas, as associações, os sindicatos etc (deve coordenar, proteger, apoiar, incrementar e incentivar a iniciativa privada, suprindo suas deficiências e retirando-sequando osgruposmenoresjápromovemdiretamente essas iniciativas, pois, do contrário, o patemalismo estatal sufocaria a liberdade e autonomia individual e a original idade da iniciativa pessoal ).

e) Princípio da Dignidade do Trabalho $\mathrm{H}_{\text {umano }}{ }^{7}-\mathrm{a}$ pessoa é o parâmetro da digni dade do trabal ho. A encarnação do Verbo (Deus assume a natureza humana) eo fato de J esus Cristo (Filho Unigênito de Deus) ter escolhido trabalhar numa profissão humilde, de carpi nteiro, mostra a digni dade do trabal ho humano, como partici pação do poder criador de Deus, e da digni dade de toda e qualquer profissão, intelectual ou manual. O trabalho do homempassaa ser caminho de perfeição humana (transformação própria e do mundo) e cristã (santificação pessoal).

f) Princípio da Primazia do Trabalho sobre o C apital ${ }^{8}$ - partindo do pressuposto de que o trabal ho humano tem uma dimensão objetiva(conjunto deatividades, recursos, instrumentos

\footnotetext{
Cfr. Encídica RerumNovarum, n. 8 e 21-22.

Cfr. Encíclica RerumNovarum, n. 15.

Cfr. Encídica RerumNovarum, n. 12-13.
} 
etécnicas de que o homem seservepara produzir bens eserviços; a obra real izada) e uma dimensão subjetiva (agir dinâmico do homem, transformando a terra, com os instrumentos do trabal ho de que dispõe; as virtudes que o trabalhador adquire ao trabalhar), o princípio norteador das relações laborais é o de que a dimensão subjetiva do trabal ho deve ter preeminência sobre a objetiva: o trabal ho, pelo seu caráter subjetivo ou pessoal, é superior a todo e qualquer outro fator de produção, em particular no que tange ao capital. Entre capital (causa instrumental) e trabal ho (causa eficiente) deve haver uma complementariedade (necessidade da justa retribuição a cada um desses fatores da produção), com a possi bilidade de partici pação dos trabal hadores na propriedade, gestão e frutos do capital.

g) Princípio da Solidariedade ${ }^{9}$ - como princípio geral, implica que os homens cultivem uma maior consciência do débito para com a sociedade, pelo patrimônio cultural, científico, tecnológico, material e espiritual recebido, retribuindo com o seu trabal ho e serviço em prol da comunidade (perspectiva da caridade, que transcende a mera justiça). Como princípio específico laboral, representa o direito dos trabalhadores de se unirem, formando associações e sindicatos, com a finalidade de defender seus interesses vitais, através de meios pacíficos, dentre os quais se apresenta como recurso legítimo (einevitável em al gumas circunstâncias) o di reito à greve.

h) Princípio da Proteção ${ }^{10}$ - que determina a

$9 \quad$ Cfr. Encídica RerumNovarum n. 31-36.

10 Cfr. Encídica RerumNovarum n. 27-29.

Revista Esmat, Pal mas, Ano 5, № 5, pag. 219 a 240 - jan/jun 2013 
intervenção do Estado para estabel ecer os limites de jornada de trabalho e as condições da prestação de serviços, para evitar a exploração do trabal hador em detrimento de sua saúde física e mental, a par de garantir-Ihe a justa retribuição pelo esforço despendido. A mulher e a criança devem gozar de uma tutela especial da lei, para que a jornada e a forma da prestação dos serviços sejam adequadas à sua comple eção física.

\section{II) AS FUNÇÕES DOS PRINCÍPIOS E SUA OPERACIONALIZAÇÃO}

Tais princípios nortearam nossa Consolidação das Leis do Trabal ho, plasmando em lei positiva o que a encíclica al bergava como princípios ${ }^{11}$.

Essa é, precisamente, uma das funções dos princípios de uma Ciência J uńdica: servir de manancial no qual se nutre o legislador para disciplinar as condutas concretas dos membros da sociedade em cada campo das relações humanas.

11 As fontes materiais da CLT, na memória de um de seus redatores, Min. Arnaldo Sussekind (1917-2012), foram basicamente as seguintes:

a) os pareceres dos Consultores Oliveira Viana (1883-1951) e Oscar Saraiva (1903-1969) do MTIC, nos processos que lhes eram submetidos sob a forma de avocatória das decisões das Juntas de Conciliação e Julgamento, constituindo jurisprudência administrativa, quando aprovados normativamente pelo Ministro do Trabal ho;

b) as teses aprovadas no $1^{2}$ Congresso Brasileiro de Direito Social, realizado em São Paulo de 15 a 21 de maio de 1941, para comemorar o cinquentenário da Encíclica Rerum Novarum, coordenado pelo Prof. Cesarino J únior (1906-1992) presidido por Getulio Vargas, que contou com mais de 500 participantes, divididos em 8 comissões, com 115 teses aprovadas;

c) as convenções e recomendações da OIT (Organização Internacional do Trabal ho), que desde sua fundação, em 1919, vinha internacionalizando as normas de proteção ao trabal hador;

d) os princípios da Doutrina Social Cristã, inscul pidos na Encíclica Rerum Novarum do Papa Leão XIII (1810-1903) (cfr. M agda Barros Biavaschi, “ O Direito do Trabal ho no Brasil: 19301942" (LTr - 2007 - São Paulo, pgs. 344-345). 
São basicamente três as funções que os princípios desempenham ${ }^{12}$ :

1) função informadora - deorientação do legislador na confecção das leis, pelos val ores queal bergam,

2) função interpretativa - de iluminar as normas jurídicas para sua exegese, sinalizando ao juiz o sentido subjacente do texto legal;

3) função normativa - de fonte supletiva da norma jurídica, diante das lacunas da lé, integrando o direito.

A função mais típica e diuturna que os princípios desempenham é a interpretativa, orientando juízes, advogados e procuradores na arte de extrair da lej o seu sentido genuíno e compositor prévio dos conflitos sociais.

Já a função mais delicada e excepcional é a normativa, uma vez que supõe extrair regra de princípio, ou seja, impor obrigação com conteúdo econômico a partir denorma orientativa e não imediatamente geradora de direito.

Ora, a função normativa depende, essencialmente, da densidade normativa que o princípio tem no ordenamento jurídico, plasmado de tal forma que é possível extrair dele regra que sirva para impor obrigações em casos concretos não especificamente previstos pela legislação.

A nosso ver, a densidade normativa de um princípio não

12 Cfr. Américo Plá R odriguez , “Princípios de Direito do Trabalho” (LTR-Edusp1993 - São Paulo, pg. 18).

Revista Esmat, Pal mas, Ano 5, № 5, pag. 219 a 240 - jan/jun 2013 
está ligada tanto à sua rel evância e essencialidade quanto à sua maior ou menor positivação num determinado ordenamento jurídico. Ou seja, é tanto mais denso e de mai or normatividade um princípio, quanto o preceito constitucional ou legal no qual estiver plasmado possuir redação que incorpore positivamente os val ores por ele al bergados.

Nesse sentido, em que pese o princípio da digni dade da pessoa humana ser dos mais importantes e relevantes, possui baixa densidade normativa, uma vez que apenas enunciado como fundamento da República Federativa do Brasil (CF, art 1 o, III), sem maiores detal hamentos.

Por suavez, eemcontraste, o princípio da inal terabil idade contratual possui al ta densidade normativa, na medida em que, insculpido no art 462 da CLT, goza de claros parâmetros, positivados no dispositivo queo al berga, tornando clara esegura a sua aplicação às mais diversas situações conflituosas. Assim, a orientação de quea al teração contratual não podeser unilateral e/ ou lesiva ao empregado resolve, como princípio-regra, inúmeros casos de alteração contratual, ligados a jornada, remuneração, condições de trabalho, mudanças de local, função, etc.

\section{III) CLASSIFICAÇÃO DOS PRINCÍPIOS SEGUNDO SUA DENSIDADE NORMATIVA}

Podemos, a partir desse prisma específico, classificar os 12 princi pais princípios trabal histas, segundo sua densidade 
normativa no ordenamento jurídico brasileiro, englobando-os basicamenteem 3 grupos, demáxima, médiaemínima densidade normativa, conforme os dispositivos constitucionais ou legais a que estejam relacionados possuam diç̧ão que especifique mais claramente regras de conduta:

\section{1) Princípios de Máxima Densidade Normativa ${ }^{13}$ :}

a) Princípio da Intangibilidade Salarial - proteção do salário na forma da lei, constituindo crime sua retenção dolosa (CF, art 7o, X), sendo vedado qualquer desconto salvo por adiantamento, previsão legal ou de norma coletiva e, no caso de dano, desde que a possi bi lidade seja acordada como empregado ou resulte de dolo deste (CLT, art. 462 e§§) ${ }^{14}$.

b) Princípio da Inalterabilidade Contratual - só é lícita a al teração contratual que se dê por mútuo consentimento e da qual não resulte, direta ou indiretamente, prejuízos para o empregado, ressalvada a reversão do comissionado ao cargo de confiança (CLT, art. 468 e $\S)^{15}$.

\footnotetext{
13 Para demonstrar a máxima densidade normativa desses princípios, procuramos nos ater à dicção legal e constitucional dos dispositivos que os albergam, ao defini-los.

14 Exemplo de aplicação concreta do princípio é o de não se admitir desconto de multa de trânsito por infração cometida pelo empregado se não há previsão contratual quanto ao desconto (cfr., inter alia, TST-RR-50900-41.2003.5.15.0033, 2ª Turma, Rel. Min. Renato de Lacerda Paiva, DJ 18/05/07).

15 Corolário desse princípio é o da estabilidade financeira do empregado, estampado na Súmula 372 , I, do TST, que não permite a retirada da gratificação de função exercida pelo empregado por mais de 10 anos, em caso de reversão ao cargo efetivo. Desvirtuamento do princípio da estabilidade financeira, levado a cabo pela SDI-1 do TST, é a manutenção da gratificação para a hipótese de descontinuidade do exercício de cargo comissionado, ainda mais quando variar a função gratificada, pois nesse caso não haveria qualquer estabilidade financeira no passado, a ser garantida para o futuro (cfr. TST-E-ED-RR-124740-57.2003.5.01.0071, SDI-1,
} 
c) Princípio da Isonomia - proibição de discriminação por motivo de sexo, idade, cor, estado civil (CF, art. 7o, XXX), deficiência (CF, art. $\left.7^{\circ}, \mathrm{XXXI}\right)$ ou espécie de trabalho (CF, art. 7ㅇ, XXXII e XXXIV), garantindo-se igual dade salarial para aqueles que trabalhem nas mesmas condições, consideradas a mesma função, local idade, empregador, qual idade técnica, sal vo diferença detempo deserviço superior a 2 anos (CLT, art. 461) ${ }^{16}$.

d) Princípio da Continuidade - proteção da relação de emprego contra despedida arbitrária ou sem justa causa, mediante indenização compensatória ( $\mathrm{CF}$, art. 70, I), bem como preservação dos direitos trabal histas em casos de al teração da estrutura jurídica da empresa (CLT, art. 10) ou mudança de proprietário da empresa (CLT, art. 448) ${ }^{17}$.

\section{2) Princípios de Média Densidade Normativa ${ }^{18}$ :}

a) Princípio da Proteção e Irrenunciabilidade - visa a proteger a parte economicamentemais fraca, que éo trabal hador, estabelecendo a impossibilidade jurídica de o trabal hador privar-

Rel. Min. Lelio Bentes Corrêa, julgado em 18/05/12).

16 A plicação prática do princípio éa garantia, aos empregados deempresas terceirizadas no setor público, das mesmas vantagens asseguradas por lei ou normas col etivas aos servidores estatais, quando laborem nas mesmas condições e funções destes, tal como estampado na Orientação J urisprudencial 383 da SDI-1 do TST.

17 Sob o prisma processual, esse princípio atribui ao empregador o ônus de provar o término do contrato de trabal ho, quando negados a prestação de serviço e a dispensa, nos termos da Súmula 212 do TST.

18 Nestes princípios, a conceituação doutrinal já supera as definições legais, não guardando perfeita sinonímia e abrangência. Na conceituação, utilizamos inicial mente os termos com que sintetizamos os princípios em nosso “Manual Esquemático de Direito e Processo do Trabalho" (Saraiva - 2012 - São Paulo, 20ª edição), para depois passar aos parâmetros legais mais próximos ao princípio doutrinário. 
se voluntariamente das vantagens conferidas pelo Direito do Trabal ho; concretizase na nul idade de cláusulas que desvirtuem ou fraudema aplicação da lei trabal hista (CLT, art 99), ou que, na livre estipulação das condições de trabalho, contraponham-se às disposições de proteção ao trabalho (CLT, art. 444) ${ }^{19}$.

b) Princípio da Subsidiariedade - pela qual a intervenção estatal no campo laboral somente se dá quando os próprios agentes sociais (sindicatos e empresas) não logram estabelecer condições de trabalho dignas e justas; concretiza-se no reconhecimento das convenções e acordos coletivos (CF, art. $7^{\circ}, \mathrm{XXVI}$ ) e na possibilidade destes estabelecerem condições de trabal ho menos favoráveis do que as legalmente previstas, em matéria de salário, pela sua redução $(\mathrm{CF}$, art $70, \mathrm{VI})$, ou de jornada, pela sua dilatação (CF, art. 7ํ, XIII e XIV), desde que promovida mediante negociação coletiva ${ }^{20}$.

c) Princípio da Boa-Fé - a conduta tanto negocial quanto processual das partes deve ser interpretada como um agir de boafé, até que se demonstre, por provas ou indícios concretos, que seagiu de máfé; assim devemser interpretados os contratos

19 A discussão que se trava em torno desse princípio diz respeito aos limites da autonomia negocial coletiva e da transação individual, aquela ligada à tutela sindical e esta à controvérsia sobre fatos, não quanto ao direito. Trata-se do recursivo debate (que será tratado mais abaixo) $\mathrm{em}$ torno da maior rigidez ou flexibilidade que o sistema protetivo trabalhista deve ofertar, para ser realmente eficaz.

20 A jurisprudência majoritária do TST tem se mostrado avessa ao prinćípio, anul ando sem número de cláusulas de acordos e convenções coletivas sobre salários e jornada de trabalho, ao arrepio das normas constitucionais que admitem a flexibilização da jornada e do salário, substituindo-se à vontade das partes convenentes e adotando um paternalismo estatal que só mantém na menoridade os sindicatos brasileiros (cfr., v.g., OJ 342 da SDI-1, sobre intervalo intrajornada, vedando sua redução mediante norma col etiva; o item II do verbete foi acrescido justamentepel a pressão fei ta pelo setor detransporte, mostrando o absurdo da intervenção judicial $\mathrm{em}$ condições especificas de trabalho, que são vantajosas para ambas as partes acordantes). 
(CC, art 113), devem se portar as partes nos contratos (CC, art. 422) e no processo (CPC, art. 14, II), presumindo-se inocente o acusado, até prova em contrário (CF, art. 50, LVII $)^{21}$.

d) Princípio da Primazia da Realidade - consiste em dar preferência à realidade fática verificada na prática da prestação de serviços em vez de ao que possa emergir dos documentos que corporificam o contrato de trabalho, quando houver discordância entre ambos; plasmado positivamente apenas na norma que determina que, nas declarações de vontade se atenderá mais à intenção das partes do que na literali idade do contrato (CC, art 112) 22 .

\section{3) Princípios de Mínima Densidade Normativa ${ }^{23}$ :}

\section{a) Princípio da Normalidade - diz respeito ao uso normal}

do direito, de modo a atingir a finalidade pela qual a norma existe, opondo-se ao abuso de direito, que ocorre quando se busca,

\footnotetext{
21 O princípio al berga noção abstrata, de ausência de malícia presumida, que deveria ser via de mão dupla na análise das relações trabalhistas, mas que tem sido aplicado uni lateral mentepeloTST, praticamentecanonizando o trabal hador (queestariasempre deboa-fé) e anatematizando o empresário (presumindo-se pautado pela cavilosidade). Vide, por exemplo, a orientação da SDI-1 do TST, de não admitir a aplicação do art. 940 do CC (que pune pela postul ação de dívida já recebi da) na seara trabal hista (cfr. TST-e-RR-14100-39.2003.5.02.0465, Rel. Min. Renato de Lacerda Paiva, DEJT 03/04/12), mas presumir mal iciosamente obstativa da aquisição da estabilidade pré-aposentadoria a dispensa do empregado 8 meses antes dos 24 meses que antecedem a sua aposentadoria (cfr. TST-E-ED-RR-3779900-06.2007.5.09.0652, Red. Des. Min. Luiz PhilippeVieira de Mello Filho, julgado em 03/05/12).

22 Também aqui o princípio deve ser aplicado como via de mão dupla, podendo ser invocado pelo empregado epelo empregador (cfr., inter alia, TST-ERR-70000-54.2008.5.15.0114, SBDI-I, Rel. Min. Aloysio Corrêa daVeiga, DEJT 28/10/11, eTST-RR-48900-90.2006.5.12.0051, 7ạTurma, Rel. Min. Ives Gandra, DJ 19/12/08).

23 Nesses princípios, a doutrina dálhes o conteúdo e, emal guns casos, aponta-lhes uma âncora no ordenamento jurídico onde ligar-se.
} 
através do exercício do direito, fim outro não previsto na lei e com ela incompatível; concretiza-se na regra da ilicitude do exercício do direito além dos limites impostos pelo fim econômico, pela boafé e pelos bons costumes (CC, art 187) ${ }^{24}$.

b) Princípio da Dignidade da Pessoa Humana - pelo simples fato de 'ser' humano, a pessoa merece todo o respeito, independentemente de sua origem, raça, sexo, idade, estado civil ou condição social e econômica; encontra-se apenas enunciado na Carta Política de 1988 como um dos fundamentos da República Federativa do Brasil (CF, art. 1o, III), sem que seja definido ou se enumere seus corolários ${ }^{25}$.

24 Caso típico de exercício abusivo de direito é a greve abusiva, por não atender aos pressupostos legais de aviso prévio e manutenção de atendimento mínimo à população (Lei 7.783/89, arts. 11 e 14), mormente quando a motivação é política e não econômica.

25 A mínima densidade normativa desse princípio, conjugada com sua máxima relevância existencial, faz com que possa embasar imposição judicial concreta, mas em casos excepcionais e desde que adotados critérios razoáveis de fixação da imposição, como é o caso do sequestro humanitário, desde que limitado ao teto constitucional das requisições de pequeno val or, como se observa do seguinte jul gado:

“I) PRECATÓRIO - EXEQUENTE ACOMETIDA DE DOENÇA GRAVE (ACIDENTE VASCULAR CEREBRAL) - PRINCÍPIOS DA DIGNIDADE DA PESSOA HUMANA E DA IGUALDADE - QUEBRA DA ORDEM CRONOLÓGICA - POSSIBILIDADE DO SEQUESTRO HUMANITÁRIO. A compreensão acerca da ordem de pagamento dos precatórios, bemcomo a interpretação quanto às prioridades epreferências constitucional mente estabelecidas, não selimita à literalidade da nova redação do art 100 da Constituição Federal, insculpida pela Emenda Constitucional 62/2009, considerada a prevalência da exegese teleológica e os princípios da dignidade da pessoa humana da igualdade, a amparar a tese do acórdão regional que manteve incólume a ordem de sequestro humanitário deferida pelo J uiz Presidente do Tribunal Regional do Trabalho da 15a Região, assegurando tratamento diferenciado à Exequente, acometida por acidente vascular cerebral, com complicações vasculares e neurológi cas sérias (perda da capacidade de locomoção e da fala e de todos os movimentos da parte direita do corpo), de modo a autorizar a quebra da ordemcronológica, conforme precedentes do Órgão Especial desta Corte.

II) LIBERAÇÃO IMEDIATA DE CRÉDITO PARCIAL, OBSERVADA A LIMITAÇÃO PREVISTA NO ART. 100, § 29 DA CONSTITUIÇÃO FEDERAL - CRÉDITO REMANESCENTE PELO RITO DO PRECATÓRIO. 1. Como o sequestro dito humanitário é feito em relação à condição do titular do precatório, desconsiderando o valor da dívida, a possi bilidade de um precatório milionário setornar al vo de sequestro integral, emface da nova 


\section{c) Princípio da Preservação da Empresa - não comprometimento da viabilidade da empresa como unidade produtiva debens eserviços paraasociedadeegeradoraderenda e emprego para os trabalhadores; concretiza-se na colocação dos val ores do trabal ho e da livre iniciativa como fundamentos da República Federativa do Brasil (CF, art1o, IV) e da justa retribuição ao capital eao trabalho (CLT, art. 766) ${ }^{26}$.}

condição de seu titular, pode comprometer tanto a viabilidade orçamentária de um Município quanto aos demais doentes graves com crédi tos judiciais a receber, daí a sabedoria da norma constitucional erigida pela EC 62/09. 2. Assima limitação prevista no art 100, § 2o, da CF, qual seja, o triplo da requisição de pequeno valor, de aplicação imediata, atende aos interesses não apenas de ambas as Partes envolvidas nesta relação jurídica, como também de outros doentes com créditos privilegiados, sendo certo que o levantamento imediato do referido valor permitirá a Exequente dele usufruir para gastos com tratamento de saúde e outros, enquanto o eventual crédito restante deverá seguir o rito do precatório, como pleiteado pela Fazenda Pública do Estado de São Paulo no presente apelo, emestrita observância ao referido preceito constitucional, a fim de evitar também o efeito multiplicador (vale dizer, o efeito dominó em milhares de outras execuções contra a Fazenda Pública), que ensejará risco de grave lesão à ordem à saúde, à segurança eà economia pública, porquanto animadas pelo sucesso dealguns, as partes acabam por tentar sobrepor o seu interesse privado ao interesse do Erário, com prejuízo para toda a coletividade 3. Assim o recurso ordinário merece provimento parcial, no particular, para limitar o val or sequestrado atéa importância equi valenteao triplo da requisi ção de pequeno valor. Recurso ordinário provido em parte" (TST-RO-14500-88.1994.5.15.0018, Órgão Especial, Rel. Min. Ives G andra, DEJT 30/03/12).

26 Paradigmático, quanto ao princípio, é o seguinte julgado:

“EXECUÇÃO PROVISÓRIA - APLICAÇÃO SUBSIDIÁRIA AO PROCESSO DO TRABALHO DO ARTIGO 475-O DO CPC - NÃO CABIMENTO - INTELIGÊNCIA DO ARTIGO 769 DA CLT. I - É lugar comumna doutrina e na jurisprudência que, para aplicação subsidiária do Processo Civil ao Processo do Trabalho, a teor do artigo 769 da CLT, é imprescindivel não haver no âmbito do processo trabalhista norma especifica que regule determinada situação que o seja naquele, emesmo assimdesde que a norma alienígena guarde compatibilidadecoma sua estrutura procedimental . II - Nessesentido, observa-sedo artigo 899, caput, da CLT di sposição expressa de os recursos teremefeito meramente devolutivo, permitida a execução provisória até a penhora, indicativa de que, ultimada a constrição judicial, não há margem para o prosseguimento de atos de expropriação, quer os que impliquem a deflagração da alienação judicial do bem que o tenha sido, quer os que envolvam a liberação de eventual depósito emdinheiro. III - Traga-seai nda à colação o teor cogentedo § 1o do artigo 899 da CLT, segundo o qual, no caso de a condenação corresponder a 10 vezes o salário mínimo regional, os recursos interponíveis o devem ser mediante o recol himento da respectiva importância, a qual no entanto só será liberada a favor da parte vencedora, por simples despacho do juiz, após o trânsito em julgado da decisão recorrida. IV - Diante desse expressivo conjunto normativo, revela-se juridicamente inviável cogitar-se da aplicação subsidiária do artigo 475-O e seus 


\section{d) Princípio da R azoabilidade e Proporcionalidade -}

diz respeito à ponderação e adequação entre fins buscados pelo legislador, juiz ou partes eos meios por elesutilizados; positivado apenas na menção à proporcionalidade da resposta em caso de agravo, com direito à indenização por dano material ou moral (CF, art.5o, V), e no devido processo legal a ser observado pelo juiz (CF, art. 5o, LIV) $)^{27}$.

Como sepodeperceber, os princípios, desenvolvidos pela doutrina, não são uniformemente positivados. Alguns ganham, no ordenamento jurídico, pleno foro decidadania, pelasua nítida positivação em dispositivo legal e constitucional. Para outros, a doutrina busca al gum suporte minimamente relacionável, para que possa aplicá-lo na solução de casos concretos, mormente quando se necessita dar suporte legal a uma decisão judicial e, princi pal mente, no caso de recursos de natureza extraordi nária, empolgar apelo cal cado no desrespeito a preceito de lei ou da Constituição.

Justamente pela dificuldade em se verificar a violação literal ediretaadeterminado dispositivo delei ou daConstitui ção,

parágrafos do CPC, sequer como intuito de imprimir celeridade à execução trabalhista. V - É queessemero intuito ou simples voluntarismojurídico não podesecontrapor aos preceitos legais que a regulam, a fim de se prevenir a indesejável consequência de ela convolar-se muma ordem jurídica fragmentada e desconexa, inteiramente descompromissada como novo paradigma do Direito do Trabalho, que se irradia para o Processo do Trabalho, de presenvação da empresa como fontederenda edeemprego. VI - Recurso provido" (TST-RR -76000-12.2008.5.03.0112, 4a-Turma, Rel. Min. Barros Levenhagen, DEJT 28/05/10) (grifos nossos).

$27 \quad$ No campo da dosimetria da indenização por danos morais, o princípio tem sido invocado diuturnamente, conhecendo-se por viol ação dos arts. 5, V, da CF ou 944 do CC recursos de revista que visem a reduzir indenizações astronômicas e desproporcionadas (cfr., inter alia, TST-RR-544-25.2010.5.03.0035, 2a Turma, Rel. Min. Caputo B astos, DEJT 15/06/12; TSTRR-111600-22.2007.5.15.0007, 5aTurma, Rel. Min. E mmanoel Pereira, DEJT 19/08/11; TSTRR-1157-88.2010.5.03.0053, 6aTurma, Rel. Min. Aloysio Corrêa da Veiga, DEJT 11/05/12). 
invocado como supedâneo do princípio, é que se percebe sua bai xa densi dade normativa.

\section{IV) BAIXA DENSIDADE NORMATIVA, ATIVISMO JUDICIÁRIO E VOLUNTARISMO JURÍDICO}

A tentação do julgador, de dar a maior efetividade aos princípios, quando estes possuem baixa densidade normativa, impondo obrigações concretas, extraídas exclusivamente dos princípios, quando inexiste preceito de lei que preveja a obrigação, é real e instigante. No entanto, gera no sistema uma proteção fictícia e uma insegurança jurídica que não compensam a supervalorização do princípio.

A essatentaçãotem-sedado onomedeativismojudiciário, ou seja, umprotagoni smo do Poder J udi ciário na conformação do ordenamento jurídico que não se limita a interpretar e aplicar as lés, mas inovar no mundo jurídico, paral elamente ao legislador. Penso que a melhor expressão para sintetizar essa tendência seria a de voluntarismo jurídico, ou seja, à míngua de norma legal específica prevendo a obrigação que se quer impor a um dos litigantes, será a vontade do juiz (e não mais a do legislador plasmada na lei) que criará o direito.

Ora, o perigo e a insegurança estão no subjetivismo necessariamente decorrente desse ativismo e voluntarismo ${ }^{28}$ :

$28 \quad$ C arlos B astide H orbach fala em "inconstitucionalidade como conceito emocional”, pelo subjetivismo voluntarista de muitas decisões que a acolhem ou rejeitam, citando impactante trecho da obra de Alf R oss: "Invocar a justiça é como dar um soco na mesa: uma expressão emocional quefazda própria exigência umpostulado absoluto. Esta nãoéuma maneira apropriada 


\section{cada juiz extrai rá do princípio que mais Iheaprouver a obrigação que menos se poderia esperar, desnorteando o jurisdicionado ${ }^{29}$. Nãopossodeixar delouvaraposturaprudenteeequili brada} de nossa Suprema Corte, nos anos que lá pontificou o Ministro MoreiraAlves, ao daratônica, no Mandado del njunção 107-DF30, do papel do Poder J udiciário no controle de constitucional idade das leis e das decisões judiciais: pode ser legislador negativo, retirando do mundo jurídico leis inconstitucionais ou reformando

de obter compreensão mútua. É impossível ter uma discussão racional comquemapela à 'justiça', porquenada dizquepossa ser questionado a favor ou contra. Suas palavras contémpersuasão, não argumento" ("A Nova Roupa do Direito Constitucional: Neoconstitucionalismo, Pós-Positivismo e outros Modismos", in "Lições de Direito Constitucional, em Homenagemao Professor J orge Miranda", coordenação de M aria E lizabeth G uimarães Teixeira Rocha e Samantha Ribeiro Meyer-P flug, Gen-Forense - 2008 - Rio, pg. 300). O mesmo se diga da invocação de princípios de baixa densidade normativa para fundamentar decisões impositivas de obrigações não previstas legal mente, que, de antemão, desejarse tomar.

29 O Ministro E ros Grau, em seu artigo "Os Princípios são Regras", publicado na col etânea "Direito Constitucional Contemporâneo - Homenagemao Professor Michel Temer" (Quartier Latin - 2012 - São Paulo, pgs. 271-278) é bastante contundente ao deplorar o uso indiscriminado dos princípios para embasar decisões judiciais sem suficiente respaldo legal: “O princípio descritivo é assimtransformado em princípio 'positivado', mas não emvirtude de lei, senão da vontadedo juiz ou tribunal que o afirme. Dai que a sua comvolação em principio de direito [=regra de direito] resulta de uma invenção dessejuiz ou tri bunal, invenção queem geral se procura legitimer sob a assertiva de que encontra inspiração doutrinal. O que levaria ao delírio de admitirmos que princípio geral do direito, na linguagem dos juristas, é princípio [regra de direito] ainda não "positivado", mas que a qualquer momento poderá vir a ser como tal formulado ou (re)formulado pela jurisprudência. O delírio conduz a descaminhos nunca vistos, no percorrer dos quais o direito positivoéreescrito pelos juízes" (pg. 277, grifos nossos). A preciosidade queo artigo recolheé uma citação deJ ean Schhmidt ("Memóire Du Droi", Paris, 1955), que retrata perfeitamente o voluntarismo jurídico, e que não resistimos a transcrever, traduzindo-a do francês: "O juiz deseja atingir um certo objetivo. A lei o impede de atingir tal fim, mas ele pensa que a solução por ele ofertada receberá a adesão da sociedade. Sem dúvida, as disposições edi tadas pel os legisladores não permitemsol ucionar o litígio no sentido desejado, mas é preciso levar em consideração esse pensamento social, do qual o pensamento do juiz é o reflexo e que the 'impõe' derrogar a lei. Como não se sentir tentado, então, a recorrer aos princípi os gerais de direito? Mas uma observação capital seimpõe: não se trata de verdadeiros princípios gerais, mas da fórmula 'princípios gerais de direito', fórmula esvaziada de seu sentido e não tendo outra utilidade que a de justificar a posição adotada. Por esse meio, o juiz alcança o objetivo al mejado ao passo que transgride a lei aparentando respeitá-la" (pg. 278). 
decisões judiciais exaradas ao arrepio da Constituição, mas não pode ser legislador positivo, substituindo-se àquele a quem a Constituição atribuiu exclusivamente a missão de, segundo a vontadepopular manifestada na representação parlamentar, criar o direito.

A tentação atual deprotagonismo, no desejo deresolver os problemas que angustiama sociedade, pela via fácil do ativismo judiciário, tem provocado inclusive atrito entre os Poderes da República. A recente decisão do STF de admitir o aborto de anencéfalos, criando nova hi pótese de exceção à norma penal ${ }^{31}$, quando o Poder Legislativo já havia rejeitado reiterados projetos de legal ização do aborto ${ }^{32}$ ea esmagadora maioria da popul ação, em repetidas pesquisas de opinião, se manifestava contrária à prática ${ }^{33}$, é exemplo disso. Após a decisão da Suprema Corte, houvepropostadeDecreto Legisl ativonaCâmaradosDeputados, para preservar a competência do Congresso Nacional contra a usurpação da função legislativa por outro Poder, cal cada no art. 49, XI, da $\mathrm{CF}^{34}$.

$31 \quad$ Cfr. ADPF-54-DF, Rel. Min. Marco A urélio, jul gada em 11 e 12/04/12.

32 O último deles, o PL 1135, de descriminalização do aborto no Brasil, foi proposto em 28 de maio de 1991, pel os deputados federais Eduardo J orge (PT) e Sandra Starling (PT), e rejeitado por unanimidade na Comissão de Seguridade Social e Família da Câmara dos Deputados. Na Comissão de Cidadania e Justiça, foi rejeitado em 9 de julho de 2008, por 57 votos a 4, sendo então arquivado.

33 Em 2007, a pesquisa da Datafolha sobre o assunto revelou que $65 \%$ dos brasileiros eram contra o aborto; jáa pesquisa do instituto Vox Populi de 2010 apresentou uma rejeição de 82\% da população ao aborto.

34 O Projeto (PDC 566/12) foi proposto em 10/05/12 pelos deputados Roberto de Lucena (PV/SP), Salvador Zimbaldi (PDT/SP) e João Campos (PSDB/GO). O art 49, XI, da $\mathrm{CF}$, que o respalda está assim redigido: “Art. 49. É da competência exclusiva do Congresso Nacional: (...) XI - zelar pela preservação de sua competência legislativa emface da atribui ção normativa dos outros Poderes".

Já registrávamos nossa perpl exi dade diante da util ização vol untarista das normas internacionais 
O sofisma que tem animado juristas e julgadores a defender esse ativismo judiciário é o de que a inércia do Legislativo em regular situações que clamariam por novo marco jurídico justificaria essa intervenção excepcional. Notase o sofisma pelo fato de que essa aparente "inércia" constitui, na realidade, vontade política contrária à mudança pretendida pela via judicial. E o paradoxo mai or é que o Poder J udi ciário, caracterizado pela sua inércia ontológica, já que só pode atuar quando provocado, pretende substituir-se ao legislador, formulando opções políticas para as quais não recebeu mandato

pelo STF, pinçando as "convenientes" e olvidando as "desinteressantes", para erigir a liberdade emvalor superior à vida, no seguintejulgado:

"HABEAS CORPUS" - DEPOSITÁRIO INFIEL - CONFIGURAÇÃO - PACTO DE SÃO J OSÉ DA COSTA RICA SOBRE DIREITOS HUMANOS (1969) E POSSIBILIDADE DE PRISÃO CIVIL - RECURSO DESPROVIDO.

1. Emque pesea existência de precedentes turmários do STF, não vinculativos, anatematizando a prisão civil de depositário infiel, a jurisprudência do TST é firme e pacifica quanto à possi bilidade jurídica dessa modalidade de constrangimento ao direito de ir e vir, não a título de pena, mas como meio extremo de pressão para resgatar bemrecebi do em depósito e afetado ao cumprimento de obrigação de caráter alimentício.

2. Paradoxal mente, o mesmo Supremo, que fez letra morta do art 4.1 do Pacto de São J osé da Costa Rica, ao referendar lei que autoriza a morte de embriōes humanos para fins de pesquisas cientificas, quando a referida Convenção Americana de Direitos IIumanos de 1969, ratificada pelo Brasil em 1992, garante o direi to à vida desde a concepção, vem esgrimir o art. 7.7 da mesma convenção, para afastar do Direito Positivo Brasileiro a prisão civil do depositário infiel.

3. A par da Constituição Federal prever expressamente a prisão civil do depositório infiel ( $C F$ art 5o, LXVII), o próprio art. 7.7 do Pacto de São J osé excepciona a prisão por descumprimento de obrigação alimentar, como é o caso dos créditos trabalhistas garantidos por depósitos judiciais. Nesse diapasão, não há de se falar em confito entre o Acordo Internacional e o Direito Interno.

4. "In casu", a condição de depositária infel da Impetrante restou demonstrada tanto nos presentes autos quanto nos da ação trabalhista principal, uma vez que assumiu o "munus publicum" de depositária, nos termos do art. 629 do CC, negligenciando a guarda dos bens penhorados e não os restituindo quando instada a fazêlo. Daí a legalidade da decretação prisional ea ausência de direito à concessão preventiva do "habeas corpus" impetrado. Recurso ordinário desprovido" (TST-ROHC-31100-86.2008.5.03.0000, SBDI-2, Rel. Min. Ives Gandra, DEJT 07/11/08). 
popular. Como um Poder técnico, com seus quadros formados fundamental mente pela seleção em concursos, com a garantia da vital iciedade e não sujeito ao control e do voto popular, pode se arvorar em representante do povo para reconstruir o direito à sua imagem e semelhança? Tratase, repito, de vol untarismo jurídico inaceitável num regime democrático de direito.

Se nem o constituinte derivado, na ação de inconstitucionalidade por omissão, permitiu que o Supremo se substituísseao Poder Legislativo, no caso denão regul amentação de preceito constitucional, como pode o Judiciário, em ações comuns, esgrimir essa pretensa inércia, para impor obrigações, calcadas exclusivamente em princípios sem suficiente densidade normativa?

\section{V) OS DESAFIOS NA APLICAÇÃO DOS PRINCÍPIOS}

Nesse contexto, não é demais lembrar que a finalidade do Poder Judiciário é pacificar a sociedade, distribuindo justiça. E, no caso do Judiciário Laboral, a finalidade é, essencialmente, harmonizar as relações trabalhistas pela justa distribuição dos frutos da produção entre capital etrabal ho.

No entanto, corre-se um perigo real, quando se envereda pelo ativismo judiciário e se quer extrair de princípios de baixa densidade normativa obrigações concretas de conteúdo econômico: acirrar o conflito social e tornar a Justiça ideologizada e parcial. 
Assim, os desafios para a Justiça do Trabalho dos dias de hoje são basicamentetrês:

a) aplicar imparcialmente uma legislação que é naturalmente parcial;

b) racionalizar o sistema recursal, sem cercear o direito de defesa 35 ;

c) efetivar a execução, sem que esta venha a ser espoliativa ${ }^{36}$.

Penso que são desafios que merecem soluções criativas e ponderadas, audazes e refletidas, que componham os meios mais aptos para se atingir os fins.

Do contrário, a invasão de competência legislativa pelo Poder J udiciário, sob o discurso fácil da integração normativa e de se extrair a máxima efetividade dos princípios jurídicos (nos casos de baixa densidade normativa do princípio), implicará

$35 \quad$ Cfr. Gilmar Ferreira M endes, "Mecanismos de Celeridade e Simplificação da Prestação J urisdicional: BreveAnáliseda Repercussão Geral eda Súmula Vinculante", eE stêvão M allet, "Celeridade da Prestação J urisdicional e Seleção das Causas a SeremJ ul gadas pel os Tribunais Superiores", in "Direito e Processo do Trabal ho em Transformação" (coordenação de Georgenor Franco Filho, Ives Gandra Filho, M aria Cristina Peduzzi, Ney Prado e Simone L ahorgue, Campus-Elsevier - 2007 - Rio, pgs. 83-126); G ilmar Ferreira M endes, "Reforma do Sistema J udi ciário no Brasil: Repercussão Geral e Racionalização J udi cial", in "A Efetividade do Direito e do Processo do Trabalho" (coordenação de Ives G andra Filho, M aurício G odinho Delgado, Ney Prado eC arlos A raújo, Campus-Elsevier - 2010 - Rio, pgs. 103-107); e Ives G andra da Silva M artins Filho, "O Critério de Transcendência no Recurso de Revista na J ustiça do Trabalho - Constitucionali dade da MP 2.226/01" , in "As Vertentes do Direito Constitucional Contemporâneo - Estudos emHomenagema Manoel Gonçal ves Ferreira Filho" (coordenação de Ives G andra da Silva M artins, América J urídica - 2002 - Rio, pgs. 379-417).

36 Cfr. os dois lados da moeda, de eficácia da execução e não espoliação, em R onaldo J osé L opes Leal, "Eficácia e Celeridade da Execução Trabalhista e a Penhora On-Line", e A ref Assreuy J únior, "Dos Abusos no Uso do Bloqueio On-Line e Alternativas de Celeridade da Execução Trabal hista", in "Direito e Processo do Trabal ho em Transformação" (op. cit., pgs. 157-180). 
verdadeiro atentado ao Estado Democrático de Direito, fundado na separação dos poderes, pois não serão os representantes eleitos do povo a inovar no ordenamento jurídico, mas técnicos não sujeitos ao controle das urnas. 